which removes the lesion, if not at the first at the following applications.

The administration of drugs, such as arsenic, iodine, and mercury, internally with the food or water was believed to be productive of the curative results shown with some laboratory experiments, but later it was found that the absorption of the lesion proceeded just as rapidly and effectively in cases where the drugs were withheld and the food alone administered. The absorption of the lesion which takes place when the animal is stable-fed is invariable. With all the cases of granuloma brought into the laboratory, from parts varying from 33 to 180 miles, the effect of stable feed and removal from pastures was most marked.

The lesions of the fifteen affected horses stabled at the laboratory vanished either completely or almost completely after varying periods under the altered environment. Some lesions which were of the acute form and others further advanced completely disappeared. A mammary lesion, with the exception of a fibrous thickening of the skin on the udder, was absorbed.

One chronic case which was returned to former pastures after apparent absorption and six months' subsequent stabling was brought back to the laboratory in a few weeks' time with the growth almost of its former dimensions though subcutaneous. After a further period of three weeks' stabling the lesion again disappeared, the only vestige of the former lesion being a slight thickening of the skin.

Another chronic growth of four years' standing almost disappeared after stabling the animal for three months.

The explanation of this absorption is difficult. Removal from pastures may play an important part in the disappearance of the lesions, but at the present time little more can be suggested than that the change of food with a suitable nutrient ratio gives an increased and better tone to the system than that which is produced by the ingestion of native pastures of poor quality and poor ratio of nutritive constituents.

\title{
THE PATHOLOGY OF THE THYROID GLAND IN WILD ANIMALS.
}

By Herbert Fox, M.D., Pathologist to the Laboratory of Comparative Pathology of the Philadelphia Zoological Garden.

THE material presented in this paper is gleaned from the autopsy material of the Philadelphia Zoological Garden Laboratory. During the ten and a half years of this laboratory's existence 3126 animals have come to autopsy, and from this number twenty have shown decided pathological changes in the thyroid gland. Unfortunately, clinical observations are lacking in nearly all the cases. The close clinical observation of wild animals is nearly impossible, as thorough examination entails catching and holding of the specimens, 
a practice always fraught with danger to the beast. Our clinical observations at this Garden are confined to a raccoon-like dog, two gray wolves, and a striped hyena, the first three with tumours, the last with a goitre. These pathological states may give exophthalmus in human beings but did not in these cases. The hyena had symptoms and signs referable to her growth. These are detailed with the pathological description. No other clinical observations were possible. Indeed, the existence of the mass in most cases was not known until autopsy.

The number of post-mortems and cases of thyroid disease are shown in the following list; only affected orders are given.

Total number of autopsies 3 I 26 .

Mammalia. Number post-mortemed ro24; number showing thyroid change 16

$\begin{array}{ll}\text { Carnivora } & , \\ \text { Felis } & , \\ \text { Canis } & , \\ \text { Procyon } & , \\ \text { Hyena } & \text { Mephitis ", } \\ \text { Marsupialia ", } \\ \text { Didelphys ", } \\ \text { Sarcophilus ", } \\ \text { Ungulata } \\ \text { Connochœetes } \\ \text { Aves ", } \\ \text { Passeres } \\ \text { Coccothraustes } \\ \text { Psittaci } \\ \text { Melopsittacus } \\ \text { Galli } \\ \text { Chrysolophus }\end{array}$

Other important groups of animals that have come to autopsy without thyroid disease being discovered are :-

$\begin{array}{lrlr}\text { Primates } & 381 & \text { Accipitres } & 109 \\ \text { Struthiones } & 19 & \text { Rodentia } & 140\end{array}$

The diagnosis made upon the thyroid in the course of the autopsy work are as follows :-

Inflammations.-

No. 282 and No. 2974 Acute, secondary by extension

" 1584 Acute, suppurative

" 566 Chronic, fibrotic

Hyperplasias.-

, 2205 ", with hyperplasia

Diffuse. Simple or parenchymatous-

\begin{tabular}{|c|c|c|c|}
\hline \multirow{2}{*}{\multicolumn{4}{|c|}{ No. 1312 Primary }} \\
\hline & & & \\
\hline , & 2205 & ", & with inflammation \\
\hline & 2320 & " & " \\
\hline & 2705 & " & \\
\hline & 2783 & $"$ & with hæmorrhage \\
\hline & 3 II 2 & ", & \\
\hline & 3119 & ", & with \\
\hline
\end{tabular}




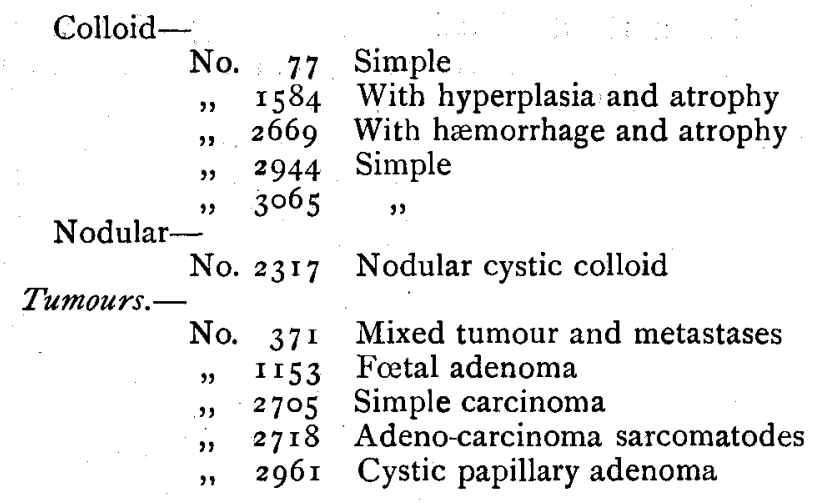

The above classification follows in a general way the methods of Marine, Lenhart, Wilson, and M'Carthy, but I have found it better for pathological diagnosis and indexing to use the terms of the older pathologists. Therefore these diagnostic terms are used in presenting the pathological description of the individual cases. I believe that the anatomico-physicological basis of the classification as used by the authorities above quoted is correct, but I do not feel that the various pathological pictures of the physiological states are as yet well enough established for us to abandon the old nomenclature.

Discussion of Findings.-It is curious that the gland has been affected by disease in adjacent structures in only two cases, one of which occurred in an atrophic colloid goitre. There have been several cases of cervical adenitis and cellulitis at the autopsy table, but with two exceptions the thyroid has not shown more than simple hyperæmia of its capsule. In two cases of heart disease there was passive congestion. The cases of acute inflammation seemed to be simple, diffuse, infiltrative, and degenerative processes. Frank chronic inflammation was observed once. The only noteworthy feature in this one case (Leopard 1566 ) is the prominent perivascular fibrosis. There were no evidences of myxœdema. The other case of chronic inflammation is in a gland the seat of pronounced hyperplasia. This will be discussed below.

The goitres or hyperplasias of the gland observed in this series may be divided into simple or parenchymatous and colloid. In both kinds there are instances of hæmorrhagic or atrophic change.

The simple hyperplasias (Nos. 1312, 2205, 2320, 2705, 2783, 3 I I 2, and 3 II9) show all variations from simple increase in the size of the epithelium, with practically no colloid, to glands with varying-sized cysts going on to atrophy both in the cyst walls and in the less well-differentiated acinus groups. In this group falls the interesting case of the dingo No. 2205. This section presents irregular acinus growth with very high epithelium, not duplicated, however, and a small amount of colloid. The appearance of the gland would suggest activity of absorption. There were no symptoms or post-mortem evidences of hyperthyroidism.

The colloid goitres are represented by Nos. 77, 1584, 2317, 2669, 2944, and 3065. There can be no sharp distinction between the two forms of hyperplasia, but the division of colloid goitre is made by 
the writer upon the amount of colloid exceeding what was considered normal and in excess of the changes in the epithelium and stroma, yet associated with alterations, hyperplasia, or atrophy in these structures. Two of the colloid goitres are accompanied by atrophy, but none of the simple hyperplasias as yet show this change. One atrophy showed fibrotic changes, the other did not. The hyperplasias were of the diffuse kind with one exception (No. 2317), in which a large single nodule was found.

The neoplasms observed permit of little comment except the compound tumour of the raccoon-like dog (No. 2718). The illustrations represent a section of the sarcoma area under the high power and the attack of the capsule by the adenoma growth. Similar outgrowths can be found in several places near the one from which the photograph was made. It seems like a simple adenoma that is assuming a malignant growth.

The mixed tumours (Nos. 2718 and 37r) are similar in that they gave multiple nodular metastases to the lungs.

\section{Details of Cases.}

No 77.-Lioness (Felis leo). Hypertrophy of thyroid gland with cystic degeneration. The thyroid gland is greatly enlarged and moderately firm. It contains colloid material. The left lobe extends down into the anterior mediastinum. The size of the thyroid is 3 by 5 inches and $I \frac{1}{2}$ inches deep. This is diagnosed as thyroid hypertrophy with cystic degeneration. It is an early autopsy and there is no section. This animal died from acute infection following a pyosalpinx. There was also a chronic splenitis and mild chronic nephritis. No chronic enlargement of the lymphatics was noted.

No. 282.- Gray wolf $t$ (Canis lupus mexicanus). Inflammation of thyroids. There is apparently an acute inflammation of the thyroids by extension from a diffuse inflammation of the neck resulting from skin,wounds. Records do not go into the death. This gray wolf showed at autopsy thickening of the tricuspid leaflet. The heart was not enlarged. There is slight degenerative chronic splenitis. The lymph glands are slightly enlarged and show mild fibrotic and pigmentary changes.

No. 37I.-Prairie wolf ? (Canis latrans). Mixed tumour of thyroid. The thyroid is enormously enlarged, partly cystic, containing about $300 \mathrm{cc}$. of blood-stained fluid. It is the size of a child's head, soft, friable, smooth, and appearing as if made up of fatty and hæmorrhagic matter. Section shows it to be a mixed tumour, doubtless from the thyroid tissue, although none of this remains. The predominating cell is round. In some fields this type only is seen, while in others the picture is entirely changed by the presence of spindle cells around large areas of definitely round cells and near blood spaces, and also large masses of round or irregular cells swollen out by oedema or mucoid change. These last areas give the appearance of cartilage. They are, however, most likely odematous cells, surrounded by or containing mucoid material. There are structurally typical metastases in the lungs. There is some suggestion at places that the orderly alveolar arrangement dominant in some fields is giving way to a disorderly one with the diffuser growth of the larger blunt-end spindle-shaped cells, The cartilage is dis- 
tinctly atypical and progressing in its formation. Besides the above a chronic splenitis was noted at autopsy.

No. II 53.-Gray wolf (Canis lupus mexicanus). Fotal adenoma of thyroid. There were two masses on either side of the midline of the neck, extending from the thyroid cartilage to about I inch from the episternal notch. They were made up of cystic cavities filled with bloody fluid, with plugs of soft tissue in them. The microscopic appearance varies considerably. In one field the cells are massed closely together, with only a very fine, hyaline, fibrillar, interstitial substance, while in another there is maintenance of the alveolus form or an irregular acinus arrangement. In the latter, as in the former

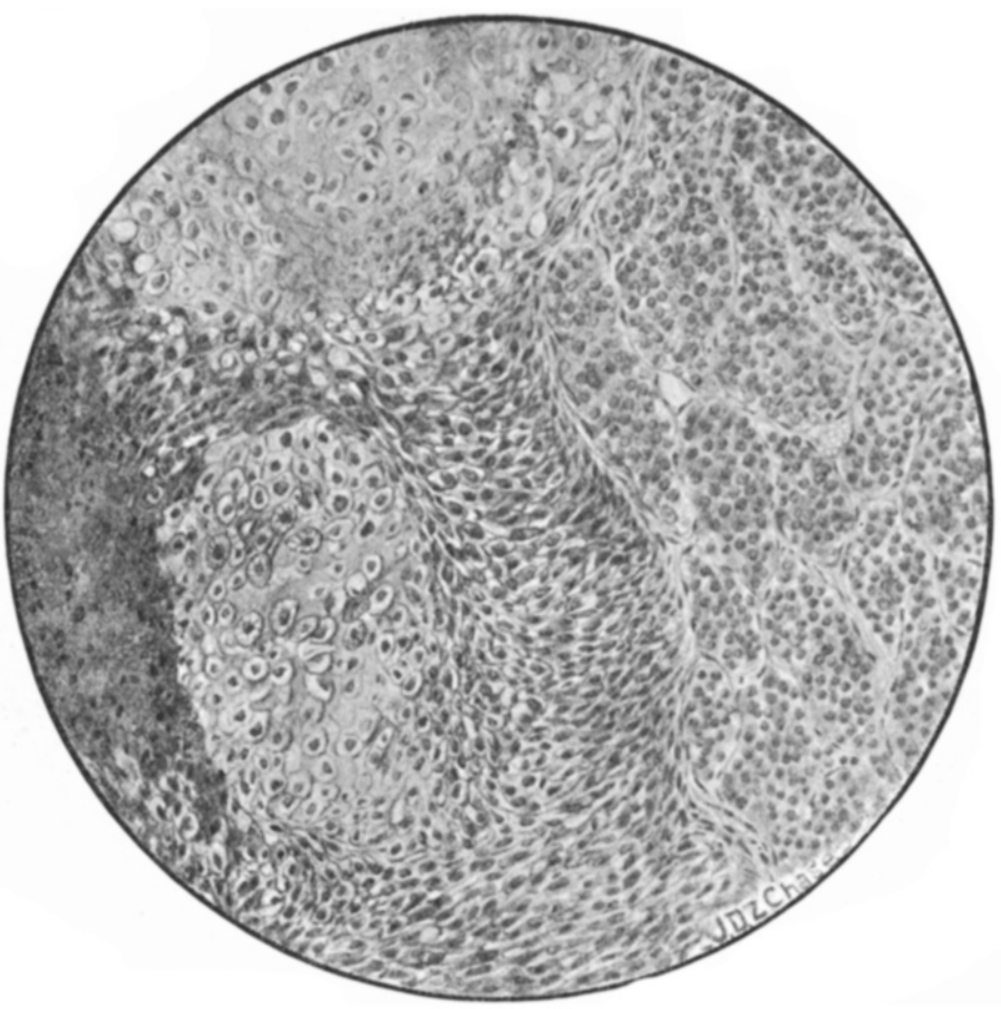

Fig. 1.

Mixed tumour from No. 371.

case, the supporting tissue is pale, hyaline, and poor in cells. The cells are small, faceted, take a purple tint in the protoplasm, and have a deeply staining, slightly eccentric nucleus. The spaces are filled with a hyaline material or with whole or degenerated blood. Colloid is scarce. The groups of more or less well-outlined acini are fairly well encapsulated. The diagnosis is given with some hesitation, as this might be viewed by some persons as a hyperplastic gland in the stage of regression. The absence of columnar cells, the vascularity, the scarcity of colloid, and the capsule lead the writer to place this mass among the foetal adenomata. 
No. I312.-Crab-eating raccoont (Procyon cancrivorus). Vascular parenchymatous goitre. The lateral lobes of the thyroid are much enlarged, the left being the size of a goose egg, the right the size of a bantam's egg. They are resilient and cystic. On opening a yellowish fluid escapes. The structure is loose, dark red, and the cavities are badly defined. The pancreas of this animal presents a chronic fibrous pancreatitis, affecting chiefly but not wholly the islands of Langerhans. Otherwise the animal is negative. Under the microscope the thyroid mass consists of loosely arranged and

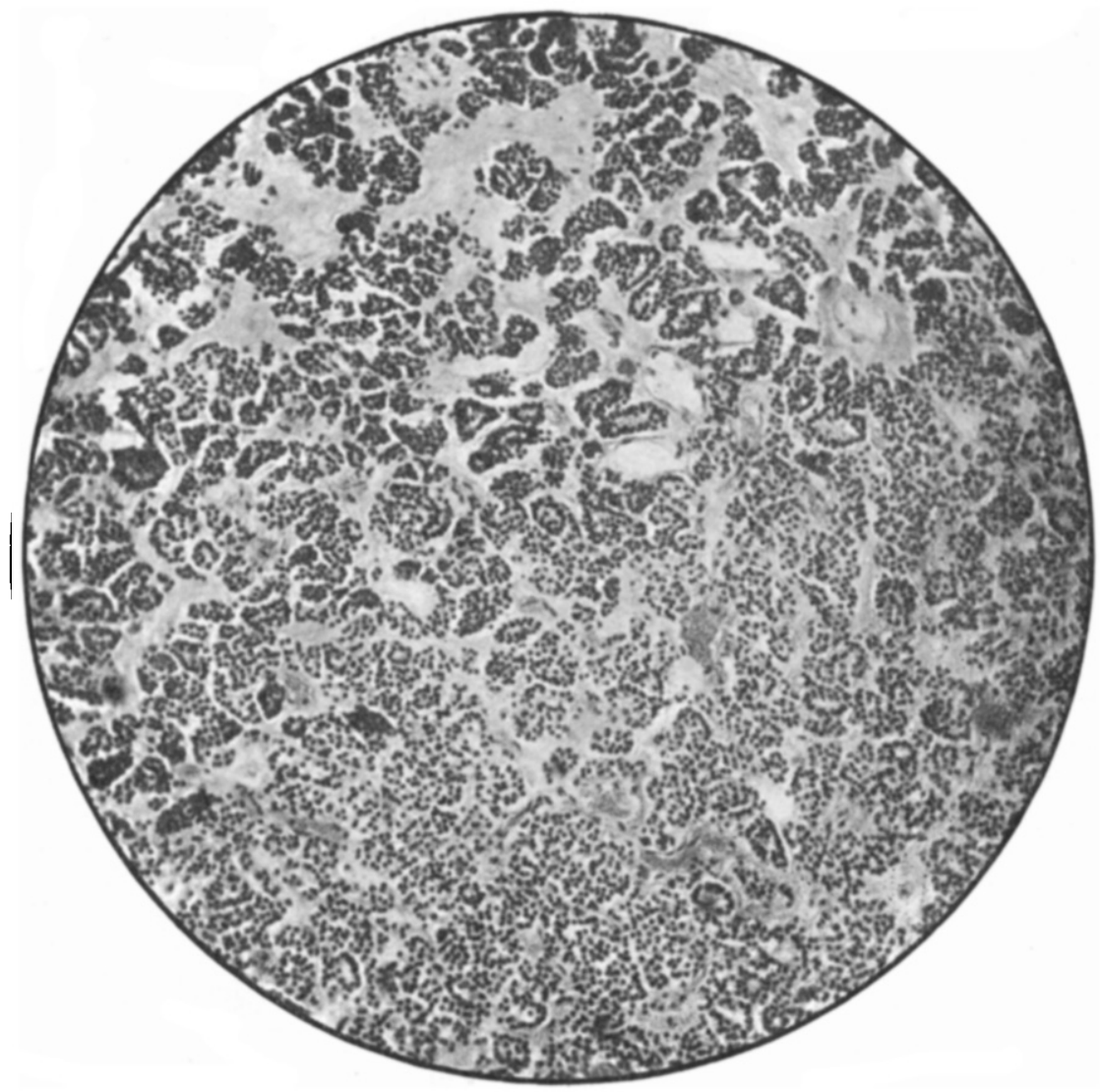

Fig. 2.

Fotal adenoma from No. 1153.

broken acini with great capillary distension. Inter- and intra-acinus extravasation and some pigment are present. There are a few cysts, some of which contain almost entirely blood, others blood, colloid, granular detritus, and organ cells. The process is one of vascular parenchymatous goitre, a hyperplasia of primary origin.

No. I 566.-Leopard t (Felis pardus). Chronic interstitial thyroiditis. On either side of the trachea the thyroid is seen as an elliptical mass, firm in consistency, purplish red in colour, lobular, about $8 \mathrm{~cm}$. in length and $3 \mathrm{~cm}$. in diameter, with an isthmus of 
similar tissue bridging the trachea. On the left side a third mass is seen distinct from the others, $3 \mathrm{~cm}$. in diameter. This thyroid is little, if at all, enlarged for this animal. The microscopical section shows the gland to be the seat of advanced interstitial change. The acini are separated by wide but varying bands of hyaline connective tissue, in which the cellular content varies. About the vessels the fibrous collar is wide and acellular. The acini are much compressed and distorted, but the cells are fairly well retained. The nuclei are

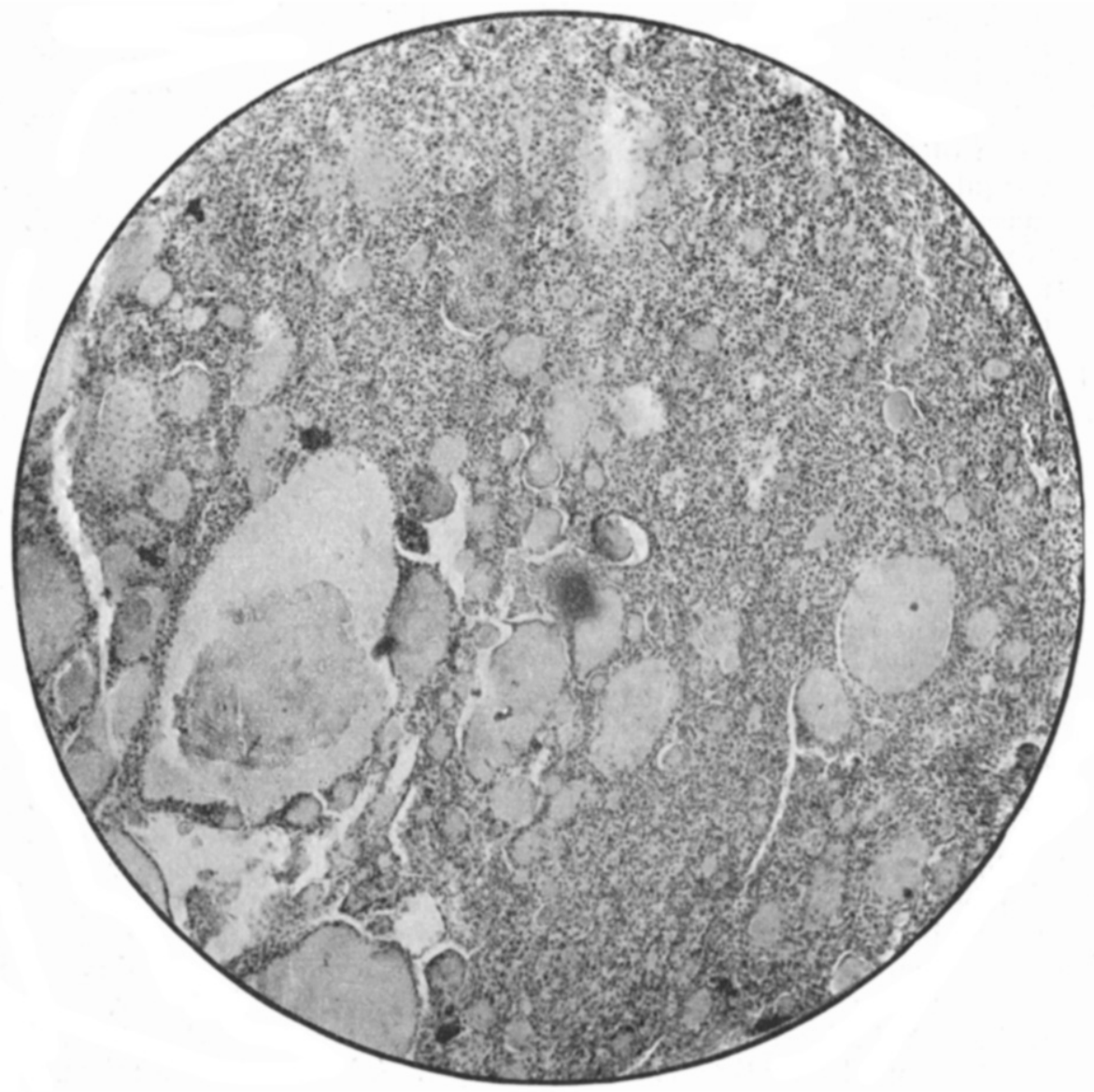

Fig. 3.

Colloid goitre with atrophy from No. 1584.

perfectly round, and in the protoplasm there is some granularity and a few vacuoles like fatty change. A very few of the acini contain colloid, and where it is present it seems inspissated and is deeply purple staining. The vessels are either small and contracted in the depths of the gland or widely distended near the periphery, some with agglomerated corpuscles or hyaline red cell masses. One cyst was seen containing a mixture of colloid and blood. Some dark yellow pigment is seen. This may have been a secondary 
replacement fibrosis and atrophy, but in such a case one would expect to find some traces of previous hyperplasia. Such are lacking. The vascular disease is a common occurrence in these animals, and this case offers nothing peculiar.

No. I 584.-Striped hyenat (Hyena hyena). Suppurating, cystic, colloid goitre. The thyroid is the seat of a cystic goitre, forming a mass as big as two fists at its greatest part, distending forward the anterior cervical muscles and compressing the trachea anteriorly and laterally. The cysts contain a brownish or yellowish fluid having the odour of decomposition. This infection has attacked the whole gland. Its point of entering is not clear, but if it be the larynx there is no visible point of egress therefrom. The microscopical section shows an atrophic, cystic, colloid goitre, some of the lobules of which show great numbers of polynuclears, coagulation necrosis, and a large amount of detritus. The colloid masses are altered by the infection, as are the non-cystic acini. Nevertheless a replacement fibrosis is evident. There has been a secondary atrophy in a colloid hyperplastic goitre. Little lining epithelium is to be found. This animal shows nothing abnormal in the rest of the organs that could not be explained by longstanding gastritis.

No. 2205--Dingo $q$ (Canis dingo). Chronic thyroiditis. The left thyroid is 4 by $I \cdot 5 \mathrm{~cm}$., and the right 3 by $\mathrm{I} \mathrm{cm}$. The left thyroid contains several cysts with thin, brown contents. Interstitial tissue is firm and fibrous. In the right thyroid there are a few small cysts of the same character. Under the microscope the gland presents an irregular architecture, but the reason for the distortion is not clear. There is definite increase in the interstitial tissue, which is quite adult, and the presence of some polygonal cells and plasma cells is suggestive that the condition is progressing. There is a large cyst at one point in the section. This is evidently of recent origin, a rupture cyst doubtless, for the contents are blood cells, thyroid cells, and broken-up colloid. There is no capsule. In one place a melting together of the gland acini has occurred, giving this field a sarcoma-like appearance. There is perivascular connective-tissue increase, but the fibrous mantle is not very cellular, rather in contrast to the tissue elsewhere. Some fields have the parenchymatous goitre appearance, while others are of definite inflammatory nature. The thyroid cells are proliferating, and, while not distinctly columnar and without active colloid formation are tall and larger than is strictly normal. Thus we have a mixture of hyperplasia and chronic inflammation with lack of colloid, a combination that might well be expected to cause symptoms, signs and changes of thyroid disease. Nevertheless the dingo was suffering from an acute general infection involving most of the tissues acutely, and leaving no trace of any chronic condition which might be the result of thyroiditis.

No 2317.-White tailed gnu $q$ (Connochotes gnu). Nodular cystic colloid goitre. The thyroid is firm and dense; cuts with resistance. At the upper pole a cyst the size of a small hen's egg is found, full of slimy fluid. Part of the cyst wall is covered by nodular excrescences which are creamy in colour and moderately firm. Under the microscope the thyroid shows a cystic colloid 
goitre which in this section is only moderately advanced, and the alveoli retain their epithelium fairly well. It is of the rather plump, low, cuboidal type, but cannot be called columnar. The gland is moderately congested. Slight fibrous thickening is to be found. There is nothing in the body of this beast which seems connected with the condition of the thyroid.

No. 2320.-Common hawfinch $\delta$ (Coccothraustes coccothraustes). Colloid goitre. The trachea and syrinx are pushed far over from the median line toward the left. The position of the right thyroid is occupied by a nodular, irregularly rounded mass, of a slaty-pink colour. It is firm, adherent to the surrounding tissues, and measures 5 by $3 \mathrm{~mm}$., thus constituting a mass almost the size of the subject's heart. Under the microscope the tumour is made up of somewhat compressed thyroid containing much colloid matter. Some of the colloid is in minute drops in an otherwise unchanged acinus. It is also present in larger collections, which dilate the acini. Nothing is atypical in the growth of the epithelium. Acini are distended and distorted by pressure and slight increase of connective tissue. The process is one of hyperplasia of the gland, with reduction or absorption of colloid. The acini are active, mitoses being frequent.

No. 2669.- Striped hyena $q$ (Hyena hyena). Hæmorrhagic colloid goitre with fibrosis and atrophy. The neck of the animal is thicker than normal. Upon stripping off the skin a black, bloody material is found in the subcutaneous tissues. The same material is found in and between the muscles. On incision this black material is seen to be fluid blood. The blood can be traced around the cesophagus, larynx, and pharynx as far forward as the hard palate, and constricts that portion of the pharynx which is close to the epiglottis, so as to obliterate the passage. The clot can be traced downwards to the sternum. It is continuous with a greatly enlarged thyroid gland which approximates to the size of a croquet ball. The gland is irregular in shape, showing knob-like elevations containing a bloody grumous material. The microscopical section consists for the most part of white fibrous tissue, whose fibres are often separated by smaller or larger areas of hremorrhage. At one end of the section is a homogeneous polychromatic material ribbed and torn as if by resistance to the knife. What little lining epithelium is present is irregular in its stratification, and does not seem to be especially proliferative. Outside of this homogeneous material the tissue is infiltrated with small round cells, between which often appears again this polychromatic material. The small round cells alluded to for the most part have no relation to the basement membrane. They can be traced in some places to positions where they are arranged in strips as lining acini. In such places especially there is a predominance of this polychromatic material. The connective tissue is increased, and, by reason of the presence of it and the cysts, the parenchyma has been compressed to atrophy, in places to obliteration. There is nothing in the body otherwise.

This tumour has been present in the animal's neck for three to five years. At various times, usually after eating, the animal has had attacks of choking with dyspnœa. At first the animal recovered in a few hours without aid. The last six or eight attacks began suddenly, and were so severe as to endanger the animal's 
life. She was caught, and upon first examination the tumour discovered. There was a firm, resilient mass about the size of an orange on one side of the midline of the neck. During manipulation this ruptured, whereupon the animal took a deep inspiration and recovered. After this the animal was caught and her neck massaged thoroughly whenever an attack occurred. If a cyst was present and was broken, as was usually the case, recovery was immediate. Apparently there was pressure upon the recurrent

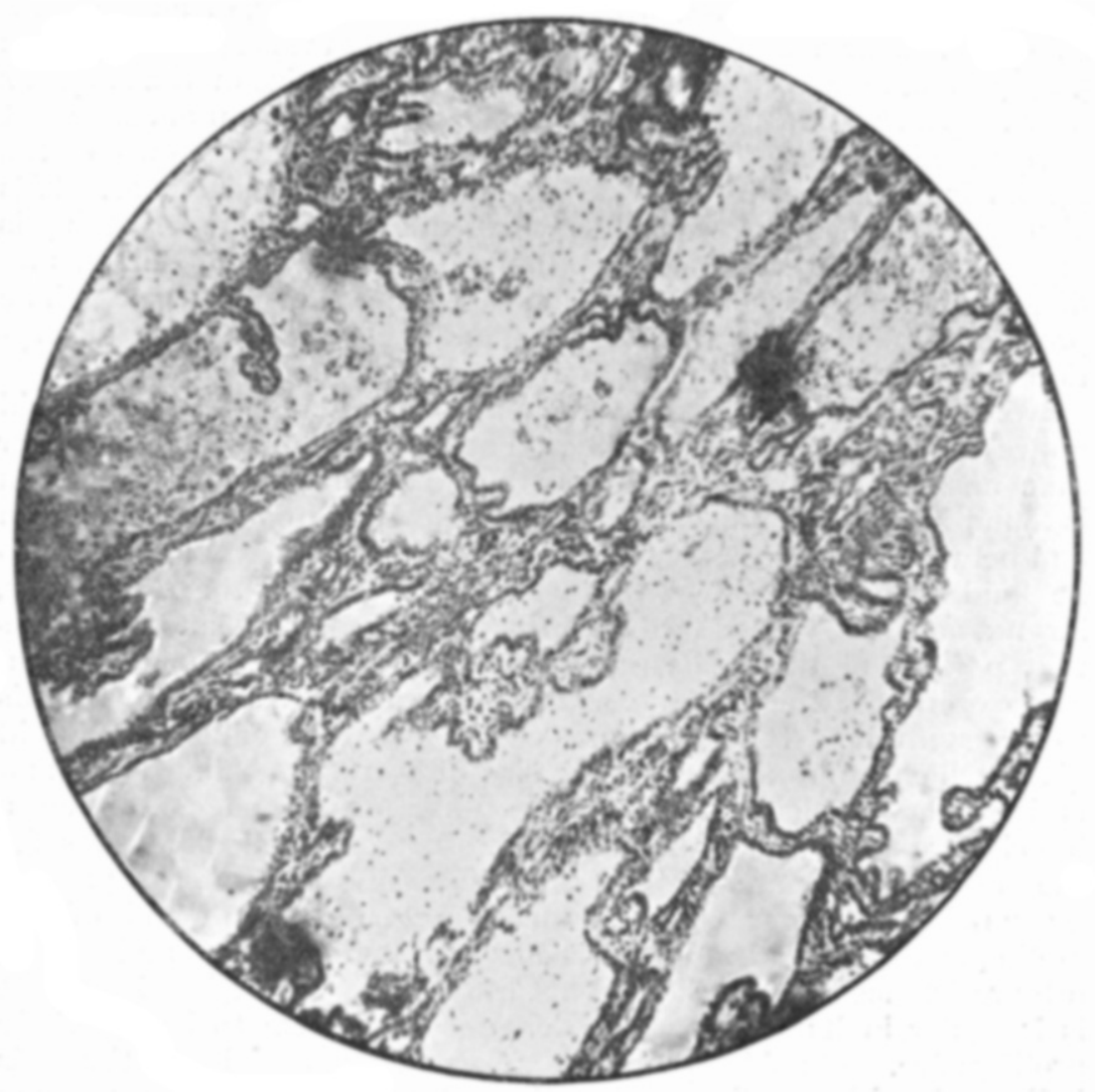

FIG. 4.

Marked primary hyperplasia from No. 2705. (Compare with fig. 9.)

laryngeal nerve. There was nothing abnormal in the mediastinum, neck, or larynx except as noted.

No. 2705.-Undulated grass parrakeet $f$ (Melopsittacus undulatus). Medullary carcinoma simplex and primary hyperplasia of thyroid. On opening the body a mass 10 by 6 by $4 \mathrm{~mm}$. is found in the upper thoracic region on the right side. A similar mass measuring 5 by 3 by $2 \mathrm{~mm}$. lies in similar position on the left side. They are identified as thyroid glands only from their position and from the numerous large vessels which radiate from them. An especially 
large vessel leads directly to the heart. The long axes extend anterio-posteriorly. The masses are of a firm, gelatinous consistency, the colour of carpenter's glue in the lower portions, shading off to a dirty canary yellow above. They have a translucent appearance in the lower portions. The surface is fairly smooth, adherent laterally and posteriorly. They are well circumscribed. At one

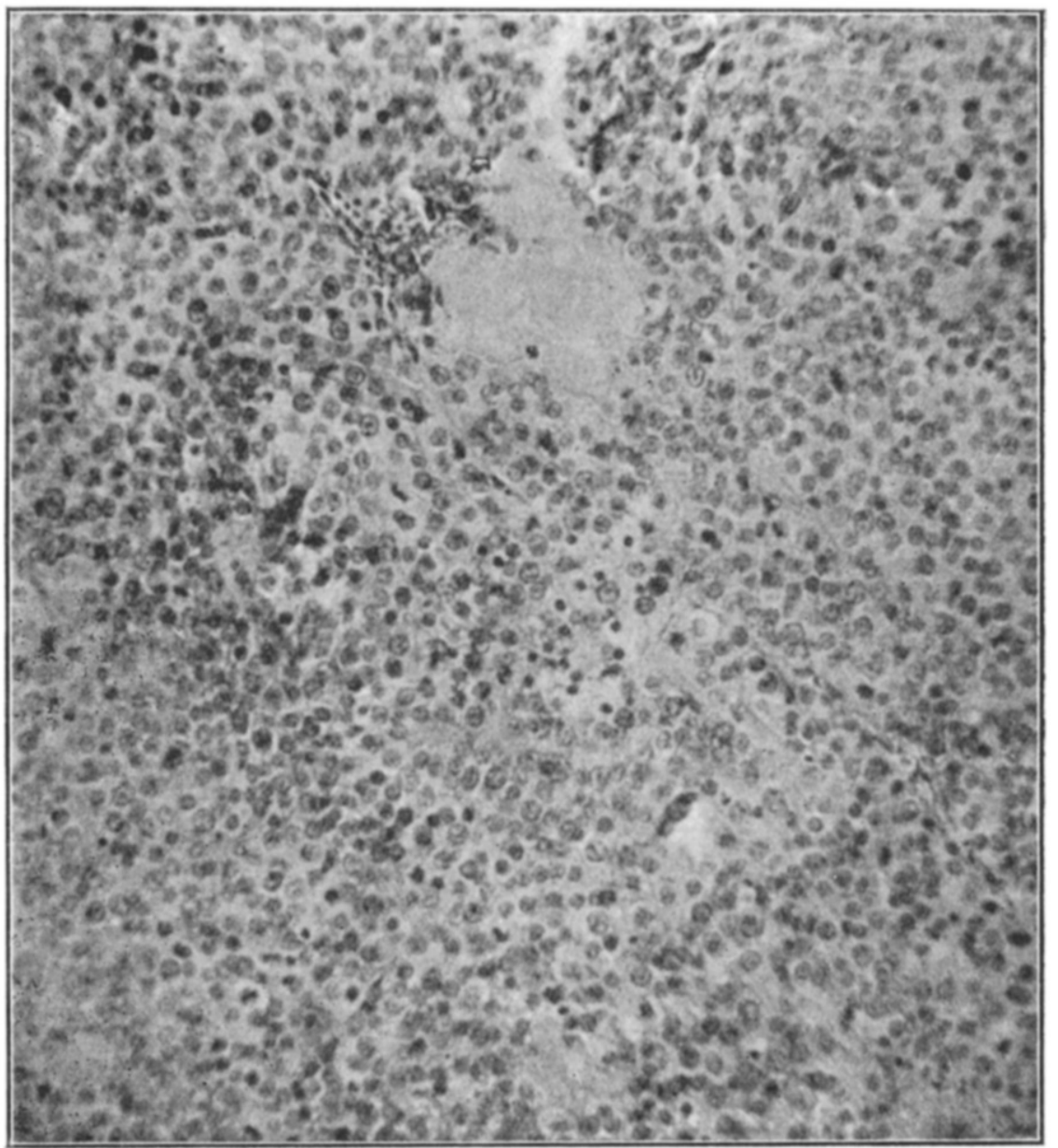

FIG. 5.

Carcinoma simplex from No. 2075 .

end of the microscopical section of the larger tumour thyroid tissue is easily identified. It varies from normal in that its spaces are often very large, contain villous projections, or are completely filled by large compound granule cells with no colloid. The epithelium is high cuboidal, and many cells are loose in the granular colloid matter 
(fig. 4). Continuous with such thyroid tissue is a large, rounded tumour. It consists of round cells with round and oval nuclei, in which many mitotic figures may be seen. An arrangement into acini cannot be made out, nor is colloid material abundant. In one or two places an irregular collection of such material may be seen with peripheral vacuolisation, but its confines are always,

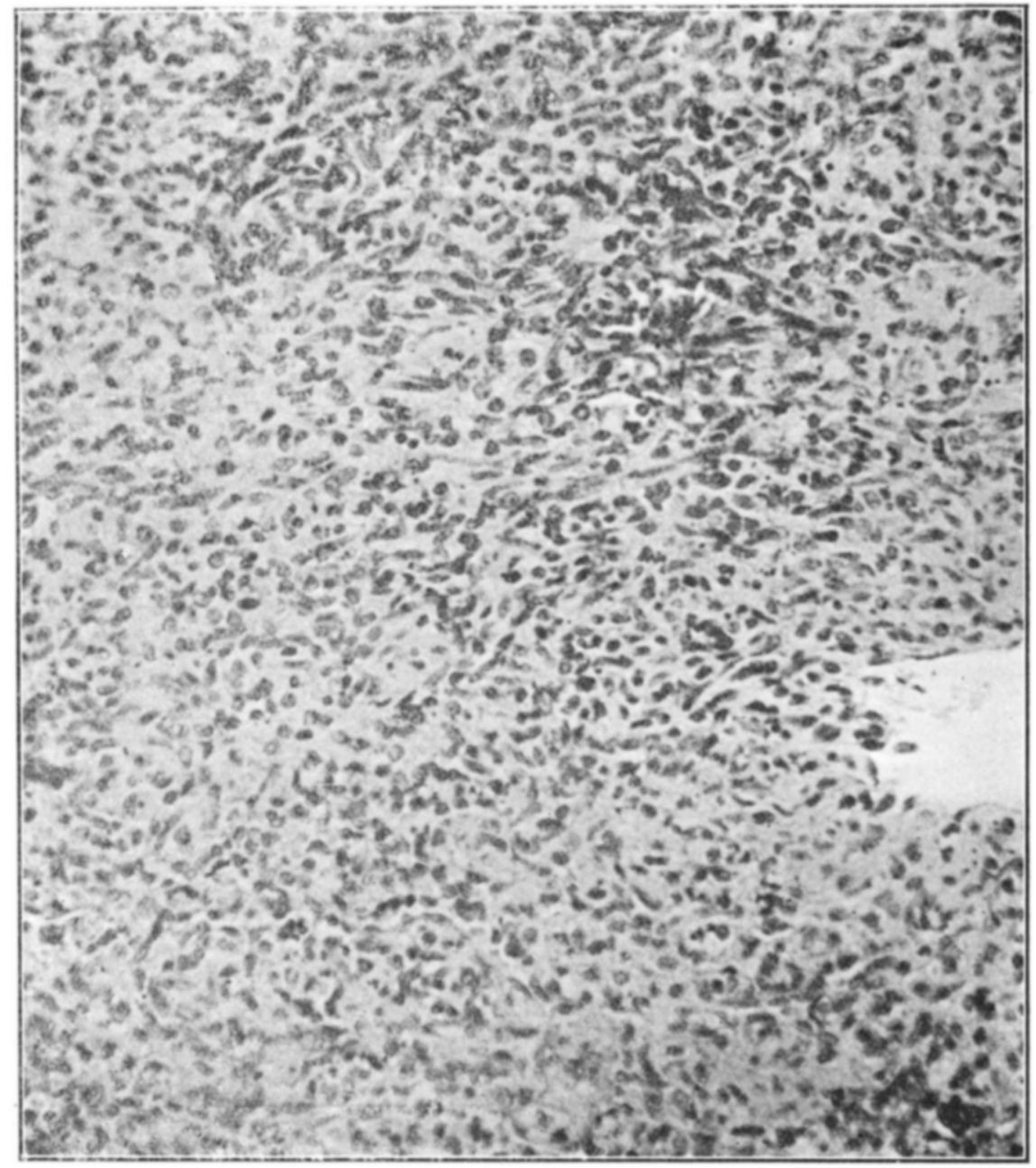

FIG. 6.

Adeno-carcinoma sarcomatodes from No. 2718. High magnification of sarcoma portion.

indefinite. As far as the section goes the mass is well encapsulated, but the lymphatics are infiltrated by the tumour cells. The tumour, too, is sharply separated from the recognisable thyroid. Irregularly scattered throughout the section are remarkable cells with nuclei three or four times the size of other nuclei. They may be hyper- 
chromatic or otherwise. This right-sided tumour seems to be a simple carcinoma with hyperplastic thyroid tissue (fig. 5).

No. 2718.-Raccoon-like dog $t$ (Canis procyonoides). Mixed tumour of thyroid-adeno-carcinoma sarcomatodes. At the level

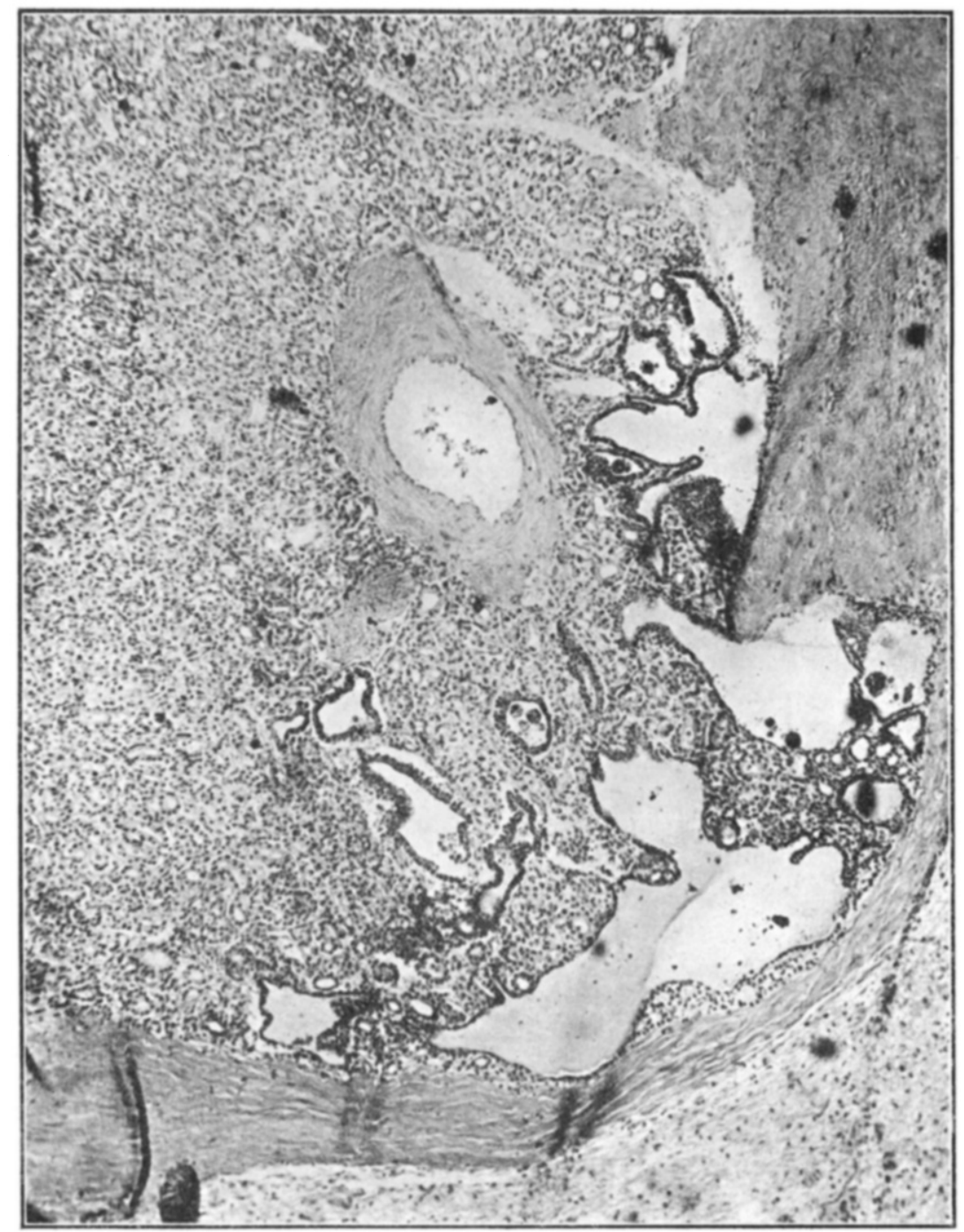

Jig. 7.

Adeno-carcinoma sarcomatodes from No. 2718. Adenomatous portion attacking the capsule.

of the thyroid cartilage on each side and removed $\mathrm{I} \mathrm{cm}$. from same is a rounded encapsulated nodule measuring 2.5 by 2 by $\mathrm{I} \mathrm{cm}$. Portions are hard, others fluctuating, suggesting cystic degeneration. 
Below these nodules are two bodies also bilateral, evidently lobes of thyroid, each measuring $5 \mathrm{~cm}$. long, $2.5 \mathrm{~cm}$. wide, $2.5 \mathrm{~cm}$. deep. They are firm, with some foci of cystic softening. From a ruptured cyst of the right lobe grumous red malodorous material exudes. Peripheries of such cysts show greenish discolorations. The bodies as a whole are greenish-black colour. They are well encapsulated, do not meet in the midline, but are joined at the lower poles by firm apparently colloid material. The microscopical section of the upper lobe is round and enclosed by a firm capsule of fibrous tissue. In places the surrounding loose areolar tissue is adherent, appearing as a delicate, loose, fibrous tissue enclosing typical polys, plasma cells, and fibroblasts. The firm, old, dense capsule is very irregular in thickness, seemingly on account of the penetration of the enclosed tumour cells to be described hereafter. Such infiltration gives the inner outline of the capsule a very irregular, bizarre appearance, and at times thins the capsule until it is reduced to nil. In one place the tumour elements appear outside the capsule at a point where a large vessel is apposed to the outside of the capsule. The appearances within this vary. In places the picture is that of carcinoma. Small, round, interspersed with larger, irregularly shaped acini are seen lined by a single layer of low cuboidal epithelium. Very frequently, indeed, these lining cells contain fine granules of golden-brown pigment, even where their lumina contains no blood. Some of the larger acini contain altered blood cells and a smooth, pink material, knife-streaked and vacuolated peripherally. In some parts of the section these acini are regular and well formed. In others they are very irregular and appear to be eroding the capsule. A second appearance concerns the connective tissue. Appearing in almost any part of the section, and bearing no regular relation to the epithelial elements or the section in general, are areas of closely packed, large, spindle cells, with hyperchromatic nuclei. In another place such spindle cells are arranged purposefully to form irregular capillaries containing blood. A third appearance results from a combination of the first two. Here there are acini between which run blood capillaries with remarkably rich and numerous embryonic lining cells. A section stained by Van Gieson's stain proves that the parts of the pink intra-alveolar material are colloid. Every graduation can be made out in tint of this material, from orange to salmon pink. It is often very difficult or impossible to state whether a given blood-filled space is a vessel or an acinus with hæmorrhage. In both structures the lining consists of flattened cells. In one there is the possibility of colloid, in the other hæmatogenous hyaline, both with peripheral vacuolisation. All through the lungs, especially under the pleura, there are dark red, rounded, firm, well-circumscribed foci, measuring from 2 to $8 \mathrm{~mm}$. in diameter. They project markedly on the pleural surface. No capsule can be made out. Upon incising they have lighter red centres and deeper peripheries. They cut with resistance and have no inclination toward a wedge shape. The microscopical section shows the walls of the alveoli thickened by a young type of cells. The nuclei of the cells lining the bronchi are prominent and in good condition. There is much coal pigment through the whole section. The air sacs are empty. 
There are several rounded nodes through the section, consisting of closely packed spindle and round cells. Blood is abundant in such nodules, both in the small-lined spaces like capillaries and in the larger necrotic foci where there is abundant blood pigment. In one place an irregular large acinus is seen containing a smooth, pink material. A large part of the interstitial tissue is diffusely infiltrated by the large round cells with hyperchromatic nuclei. The areas in the lungs, while bearing some resemblance to the sarcoma portions of the thyroid tumour, cannot be wholly identified therewith. The picture in the lungs is closer to the angio-sarcoma, or at two places to the endothelioma. I am inclined to view them as histologically different tumours, but their multiplicity and wide distribution suggest metastases of the sarcoma parts of the thyroid mass. At the autopsy this animal showed fatty degeneration of the liver and kidney, acute diffuse and degenerative splenitis, and submucous hæmorrhages in the stomach. The liver is slightly increased in size otherwise than by the metastases. Spleen and lymph nodes are enlarged by congestion only.

No. 2783.--Raccoon-like dog $q$ (Canis procyonoides). Hæmorrhagic parenchymatous goitre. The right thyroid is lower than the left. Both are 4 by 3 by $2 \mathrm{~cm}$., soft, resilient, with a dense gray capsule. Section shows cysts filled with blood separated by pale septa or soft tissue of varying thickness. The microscopical section is made up largely of slightly enlarged acini, in most of which a slightly eosin-stained hyaline collection is found. There are a few cysts containing a thrombus and hæmorrhage. There are no typical colloid cysts. Some scars from old hæmorrhages may be seen. There is much free blood in and between the acini. Blood pigment free and in the granule cells is abundant. Some acinus cells show fat droplets. This animal gave a pathological diagnosis of hypertrophic cirrhosis of liver, acute general infection, chronic interstitial nephritis, hypertrophy of the heart with.acute myocarditis, chronic lymphadenitis with acute exacerbation, and acute splenitis. It would seem that there are in the animal changes which could be referred to the thyroid disease. There are distinct hyperplastic changes with increase in size and height of the epithelium. From the absence of colloid cysts it would seem that this is a primary process.

No. 2944.-Golden pheasant + (Chrysolophus pictus). Colloid goitre. Both thyroids are larger than normal, measuring 4 by 3 by $3 \mathrm{~mm}$. They are not of the usual yellow colour, but rather have a beef-steak red colour. They have a translucent appearance and cut easily. Most of the microscopical section consists of closely placed acini containing smooth, faint-ribbed material. Most of the acini are small, but occasionally one is found occupying almost the entire lowpower field. At one side of this mass the normal parathyroid is present. This is a colloid goitre in which practically no acini remain. The epithelium is flattened in all parts of the section, but in some acini there is no epithelium, merely a fine fibrositic line separating the colloid collections. There is as usual a little round cellincrease at places. This seems like a colloid goitre, with regression of epithelial activity and atrophy. Some parathyroid tissue at the side shows an increase in interstitial septa, the glandular cells being 
unaffected. This animal gave a pathological diagnosis of chronic parenchymatous nephritis with psammoma bodies and chronic typhlitis.

No. 296I.-Tasmanian devil (Sarcophilus ursinus). Papillary cystadenoma of thyroid. The thyroid-parathyroid mass is $2.5 \mathrm{~cm}$. long on the right and $2 \mathrm{~cm}$. on the left. Both are $\mathrm{I} \mathrm{cm}$. wide and thick. The parathyroids are small, pale grey masses attached to the upper and lower poles of the capsule of the thyroid on each side. The thyroids are nodular masses of varying consistency, and on section

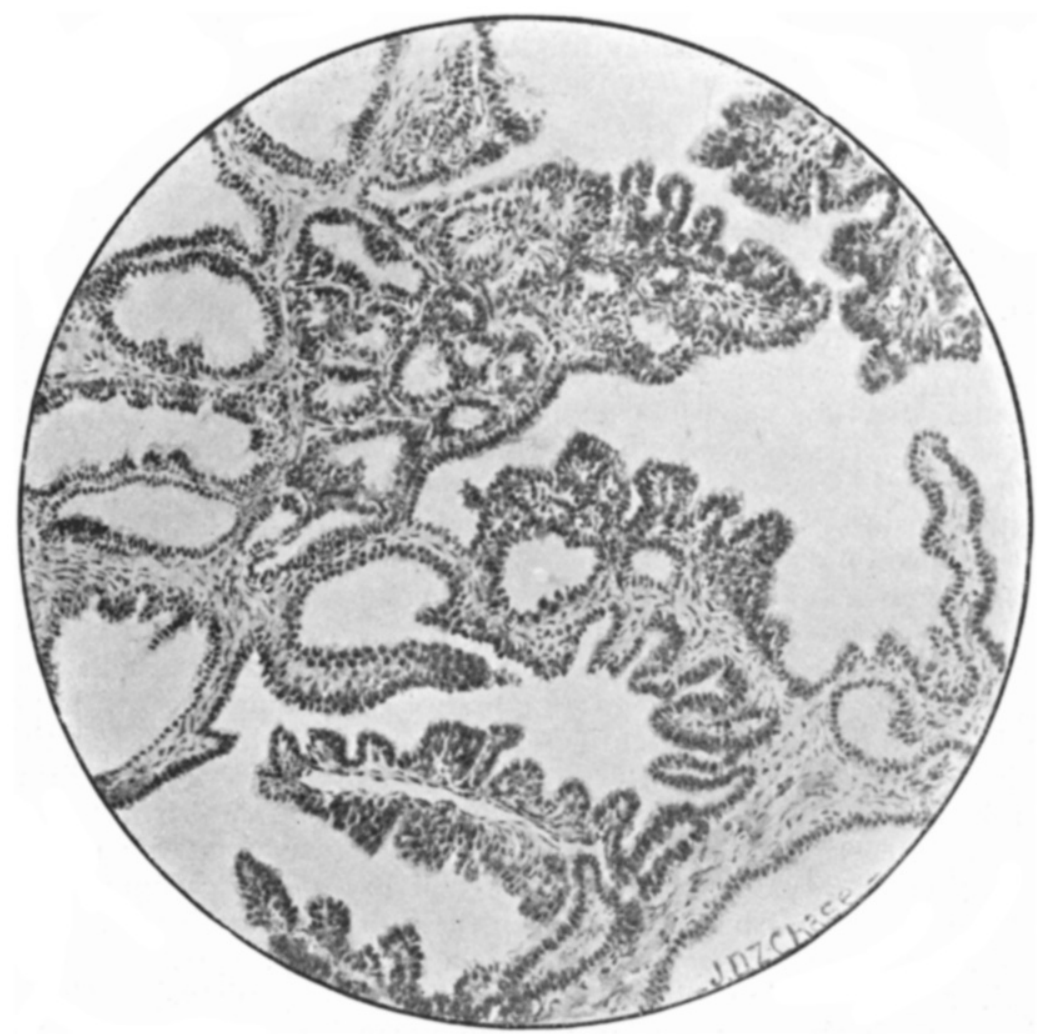

FIG. 8.

Papillary cyst-adenoma from No. 2961.

show small cysts containing bloody material and solid greyish and yellowish areas. The microscopical section (right side) shows a large area composed of a papillary cyst-adenoma and a smaller bit of tissue attached to this in which the chronic thyroiditis is prominent, but there is an attempt at epithelial reduplication and papilloma formation. There is, curiously enough, no colloid in the section.

No. 2974-Common skunk -CMephitis mephitica). Acute suppurating thyroiditis. There is a rather healthy ulceration on the right 
side of the neck which leads down to a cellulitis extending over the humero-scapular joint and under the scapula. The right thyroid shows complete phlegmonous destruction, and the trachea is much congested, but there is no bronchitis. The mouth is free from any

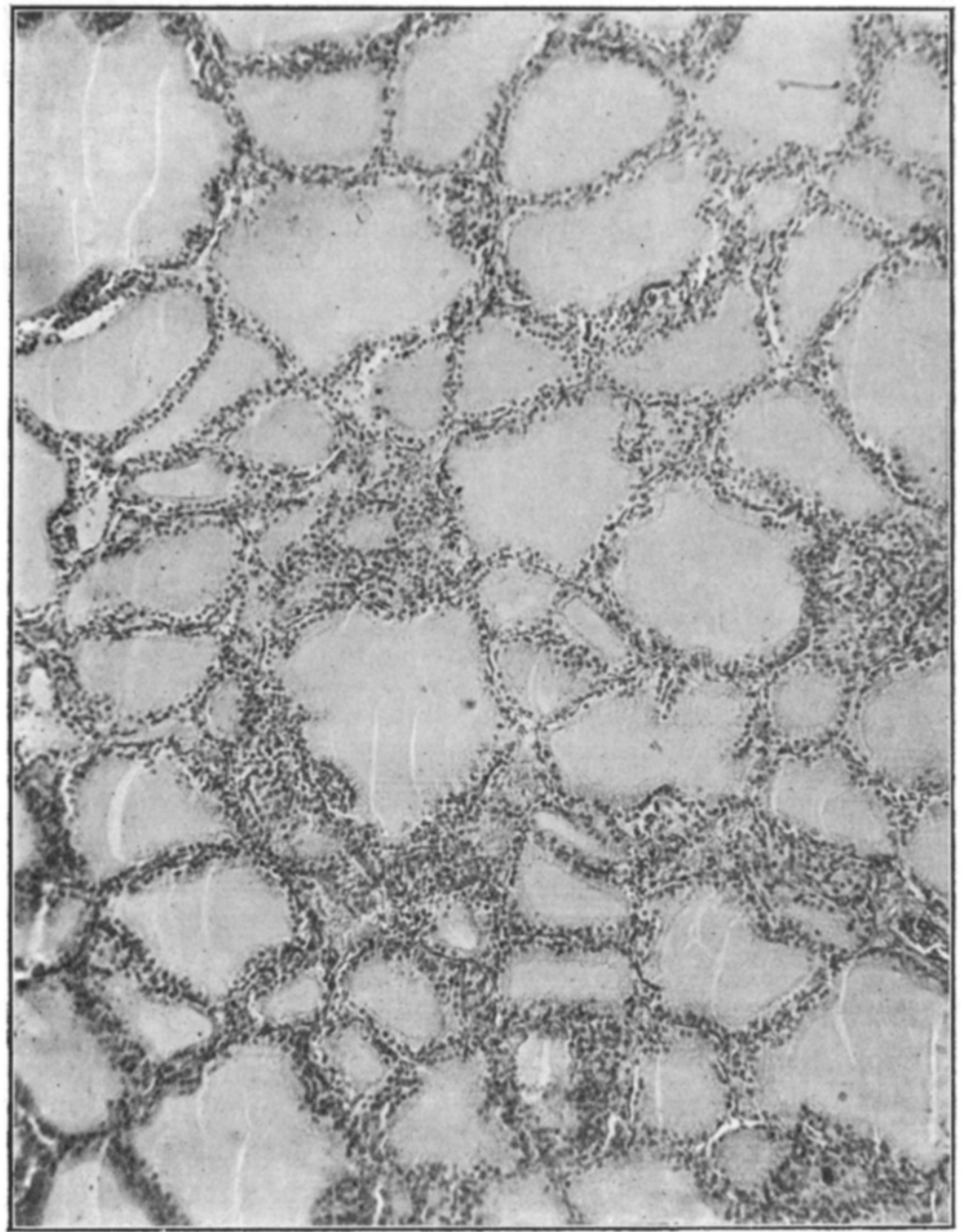

FIส. 9.

Simple hyperplastic colloid goitre from No. 3065. (Compare with fig. 4.)

portal of entry for this infection. The predominating organisms are staphylococci and streptococci.

No. 3065.-Common opossum $q$ (Didelphys virginiana). Simple colloid goitre. Both thyroids are slightly enlarged, measuring about 
4.5 by 2 by $1.5 \mathrm{~cm}$. They are dull purple, with dilated capsular vessels. The section surface is dark red mottled with paler areas, the latter being in the form of well-outlined circular homogeneous areas. The consistency is homogeneous. There are no cysts. The microscopical section shows active hyperplasia of the epithelium, with the acini solidly filled with colloid. Here and there is a loose cell in the colloid, but for the most part the acinus walls are quite regular. No other condition of importance was found in the animal, death having occurred from acute enteritis.

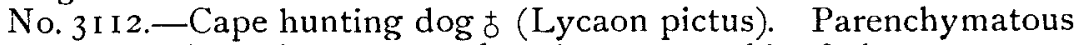
goitre. The thyroid measures 5 by 2 by $I \mathrm{~cm}$., and is of a homogeneous purple colour. The microscopical section shows hyperplasia with decrease in the size of the acini, increase in the height of the epithelium, and condensation of the colloid, which is present in variable amount throughout the section. There is no increase in connective tissue. This animal died of acute catarrhal enteritis and chronic ulcerative gastritis. There was also congestion of the kidneys and lungs, probably dependent upon slight dilatation of the heart. There was no loss of compensation and no hypertrophy.

No. 3 I I9.-Common raccoon $q$ (Procyon lotor). Parenchymatous goitre. The right thyroid measures 4 by 2.5 by $2.5 \mathrm{~cm}$., the left 2 by $\mathrm{I}$ by $8 \mathrm{~cm}$. The left is uniform, homogeneous grey-red, and at the upper and lower poles, just under the capsule, is a paler grey-red, well-outlined area of the same consistency as the thyroid. The right thyroid is cystic. The capsule is dense grey, and the whole organ is of a slightly flattened egg shape. On section the organ shows cysts of varying size, the largest being about one third the bulk of the gland. These cysts contain a dark fluid with masses about the consistency of fresh lymph. The interstitial tissue is in the form of brown mixed with areas of dark red, probably blood. The microscopical section shows irregular increase in the size of the cells with a small amount of colloid, rather palely staining where the colloid is not compressed or deeply staining where the change seems to be due to the pressure of large cysts, the contents of which are blood and fibrin. The growth of the thyroid cells is chiefly in their height, but there are several fields where they are growing apparently in an unrestricted manner. There is, however, no other evidence of malignancy. This may be due to distortion by recent hæmorrhage. In two cysts, without colloid, there is a distinct papillary growth from the basement membrane. 